\title{
Análise do Processo do Cuidar na Atenção Básica: Deslocando o Olhar do Eu-Trabalhador
}

\author{
Thalita da Rocha Marandola ${ }^{1}$, Célia Maria da Rocha Marandola ${ }^{1}$, \\ Josiane Vivian Camargo de Lima ${ }^{1}$, Katia Santos de Oliveira ${ }^{1}$, Maira \\ Sayuri Sakay Bortoletto ${ }^{1}$ e Regina Melchior ${ }^{1}$
}

\author{
${ }^{1}$ Universidade Estadual Londrina, Brasil | thalitamarandola@uel.br; \\ celiamarandola@hotmail.com; josivivian@gmail.com; katia.fit@gmail.com; \\ mairuska@gmail.com; reginamelchior@gmail.com | https://orcid.org/0000- \\ 0002-5042-6873; https://orcid.org/0000-0002-7426-9729; \\ https://orcid.org/0000-0002-4448-3548; https://orcid.org/0000-0003-3622- \\ 7955; https://orcid.org/0000-0002-7458-389X; https://orcid.org/0000-0002- \\ 7198-601X;
}

Resumo: A Atenção Básica (AB) é o principal acesso da população as serviços do Sistema Único de Saúde brasileiro, é neste campo que a Estratégia Saúde da Família (ESF) atua com a promoção, prevenção, reabilitação, produzindo o cuidado com o usuário pertencente a sua área de abrangência. A ESF compõem o território dos usuários e está próximas as famílias e são nestas relações que há produção do cuidado. Conhecendo este contexto, é relevante discutirmos as práticas de cuidado realizadas nestes espaços, de forma a contribuir com o processo de trabalho destas equipes e apoiá-los na produção do cuidado em saúde. Objetivos: analisar a produção do cuidado realizado pelos trabalhadores de uma equipe da Estratégia Saúde Família, de um município de grande porte, no sul do País. Métodos: Tratase de uma pesquisa interferência, na perspectiva cartográfica, que utilizou-se do usuário cidadão guia e tenda do conto para acessar as formas como o cuidado é produzido. Fol escolhida uma família cidadã guia a partir das indicações da equipe de ESF de uma UBS. O acompanhamento ocorreu no período de 2016 e 2017. Os encontros foram registrados por meio de gravações em áudio e diário de campo. A tenda do conto foi uma ferramenta utilizada em uma das reuniões de equipe como um dispositivo disparador para a reflexão do trabalho. Resultados e conclusão: a complexidade do caso apresentado pela família cidadã guia suscitou a discussão do processo de subjetivação a que estamos sujeitos, e que produzem olhar armado sobre o usuário e suas necessidades em saúde de forma a interferir diretamente na produção do cuidado deste indivíduo/família. Identificamos que uma forma de apoiar o trabalhador em saúde nesta desconstrução do olhar armado é incentivando a reflexão do processo de trabalho diário. E a educação permanente em saúde (EPS) é apresentada como uma alternativa neste processo.

Palavras-chave: Produção do Cuidado; Atenção Básica; Cartografia; Processo de Trabalho; Usuário Cidadão Guia.

\section{Analysis of the Process of Care in Primary Attention: Shifting the I-Worker Look}

Abstract: Primary Care $(A B)$ is the main access of the population to the services of the Brazilian Unified Health System, it is in this field that the Family Health Strategy (FHS) works with the promotion, prevention, rehabilitation, producing care with the user belonging to its coverage area. The FHS comprise the territory of the users and the families are close and it is in these relationships that care is produced. Knowing this context, it is relevant to discuss the care practices carried out in these spaces, in order to contribute to the work process of these teams and support them in the production of health care. Objectives: to analyze the production of care provided by workers of a family health strategy team, in a large municipality, in the south of the country. Methods: This is an interference research, from a cartographic perspective, which used the citizen user tale guide and tent to access the ways care is produced. A citizen guide family was chosen based on the indications of the FHS team of a UBS. The monitoring took place between 2016 and 2017. The meetings were recorded through audio recordings and a field diary. The tale tent was a tool used in one of the team meetings as a trigger device for the reflection of the work. Results and conclusion: the complexity of the case presented by the citizen guide family raised the discussion of the subjectification process to which we are subject, and which produce an armed look at the user and his health needs in order to directly interfere in the production of care for this individual/family. We identified that a way to support the health worker in this deconstruction of the armed gaze is to encourage reflection on the daily work process. And permanent health education (EPS) is presented as an alternative in this process.

Keywords: Care Production; Basic Attention; Cartography; Work process; User Citizen Guide. 


\section{Introdução}

No Brasil, a Atenção Básica $(\mathrm{AB})$ tem se configurado como terreno fértil para as diferentes experimentações que conduzem à produção contínua do cuidado - mantendo-se como principal porta de entrada do usuário ao Sistema Único de Saúde (SUS), embora não seja a única (BRASIL, 2012; p. 9).

As equipes de saúde que atuam na $A B$, seja na Unidade Básica de Saúde (UBS) e/ou na Estratégia Saúde da Família (ESF) são responsáveis pelo acompanhamento do usuário em todo o ciclo vital a partir do desenvolvimento de ações ligadas à promoção da saúde, prevenção de agravos, tratamento e recuperação da saúde individual/coletiva - com foco na produção do cuidado (BRASIL, 2012; p.19).

Por sua vez, o cuidado é formado por um leque de ações, procedimentos, fluxos, rotinas e saberes que se complementam ao mesmo tempo em que se disputam e, embora inerente ao processo de trabalho dos profissionais da saúde, o cuidado é de responsabilidade, também, dos familiares, dos amigos, e do próprio usuário (CECÍLIO, MERHY 2003; FEUERWERKER, 2013).

O processo de trabalho tem como principal objetivo a projeção de resultados que buscam atender as necessidades e expectativas do usuário conforme sua organização social e, se caracteriza pelo conjunto de ações e a maneira como desenvolvemos nossas atividades profissionais buscando transformar o "objeto" em algo melhorado e/ou mais consciente (FARIA, et. al, 2009; p.21).

Para o desenvolvimento do processo de trabalho das equipes de saúde onde o usuário é o principal objeto, o modelo médico-hegemônico de atenção, ainda se constitui em barreiras para este usuário, que busca seu cuidado, sendo comum: a insatisfação/insegurança dos usuários com o atendimento recebido e com a maneira com que os profissionais de saúde operam os serviços - utilizando-se de práticas históricosocialmente determinadas pela ação médico-hegemônica (RODRIGUES; ARAÚJO, 2003).

Neste modelo de atenção, a baixa efetividade das ações desenvolvidas pelas equipes de saúde interfere diretamente na capacidade de atendimento às demandas por saúde individual e coletiva dos usuários do SUS (RODRIGUES; ARAÚJO, 2003). Sendo necessária uma reflexão das equipes de saúde acerca do processo de trabalho e suas práticas de saúde onde os trabalhadores possam se colocar em análise no intuito de evitar prejuízos para o cuidado em saúde produzido nos encontros entre usuários e trabalhadores de saúde.

Neste sentido, a Educação Permanente em Saúde (EPS) aparece como uma potente estratégia para a modificação das práticas de saúde e pode ser colocada pelos serviços de saúde como estruturante, inclusive, das eventuais necessidades de atualizações técnicas. Pois, muitas vezes por trás de uma pseudo-necessidade de atualização estão outros problemas do processo de trabalho daquela equipe, que vão desde estrutura física até a forma de organização do trabalho e os desafios do trabalho em equipe (MARANDOLA et. al, 2009).

Diante do exposto e tendo como subsídio uma pesquisa na qual os pesquisadores experienciaram os caminhos percorridos pelo usuário em sua busca pelo cuidado em saúde, este artigo tem como objetivo analisar um processo de educação permanente executado a partir dos resultados desta pesquisa.

\section{Metodologia}

Este artigo é produto da Pesquisa intitulada como Observatório de Práticas de Cuidado em Redes Atenção Domiciliar e Atenção Básica que foi aprovada no comitê de ética em Pesquisa envolvendo Seres Humanos da Universidade Estadual de Londrina sob o № 1.643.145 datado de 20 de julho de 2016, em consonância com as orientações do CNS № $466 / 2012$. 
Contou com apoio e financiamento da Fundação Araucária para o grupo de pesquisa e com auxílio financeiro ao pesquisador principal por meio da bolsa Capes. A pesquisa em campo foi realizada entre os meses de agosto/2016 a agosto/2017.

Com o objetivo de analisar a produção de cuidado realizado pelos trabalhadores de uma equipe da ESF, de um município de grande porte no sul do País, optou-se pela estratégia cartográfica que possibilita 0 in-mundizar-se com o processo de trabalho junto com 0 trabalhador já in-mundizado, desta forma produzirmos juntos a pesquisa em nós, a reflexão de si. Tal modo de pesquisar:

"Consiste na produção de questionamentos sobre a própria prática do pesquisador, in-mundo. Análise que se amplia no movimento de produção do sujeito em ato e de suas afecções, pertença, referências, motivações, investimentos libidinais, bem como das relações de saber poder sempre produzidas nos encontros entre o pesquisador e seus objetos. Aqui se abre espaço para a experiência, para o exercício de produzir um conhecimento interessado, implicado na transformação de práticas e saberes que, por exemplo, prescrevem formas universais de se andar a vida" (ABRAHÃO et. al, 2013, p. 156).

Este espaço para a experiência produz caminho para a pesquisa de interferência (Moebus, 2016), pois nela consideramos que todos somos pesquisadores, não só a equipe de pesquisa, mas também os trabalhadores de saúde e os próprios usuários. Assim, todos pesquisadores, ao mesmo tempo que experienciam o campo, fazem reflexões e análises sobre o vivido.

A cartografia, perspectiva metodológica utilizada, trata-se de um caminho que se constitui segundo o que é experimentado em ato. Para Deleuze, Guatarri (2000) cartografar é o ato de construir mapas não estáticos: mapa "aberto, conectável em todas as suas dimensões, desmontável, reversível, suscetível de receber modificações constantemente" (p.30). Para Rolnik (2016), a cartografia

"é diferente do mapa, é inteligibilidade da paisagem em seus acidentes, suas mutações: ela acompanha os movimentos invisíveis e imprevisíveis da terra - aqui movimentos do desejo -, que vão transfigurando, imperceptivelmente, a paisagem vigente" (p.62).

Esta construção é produzida nos encontros, a cada acontecimento em ato, pois, novos atores são envolvidos no processo da pesquisa, e assim, a mesma vai se efetivando e o produto destes encontros são pistas para um novo movimento.

Como dispositivo para o trabalho de campo foi utilizado o usuário cidadão guia, este dispositivo já utilizado em outras pesquisas, nomeado como usuário guia (SILVA, 2007; MERHY, 2011) auxilia na escolha dos caminhos a serem percorridos durante a produção dos dados. O termo usuário guia foi descrito por Merhy et. al, (2011) num estudo sobre Saúde Mental, no qual estes autores se espelharam na metodologia de uma historiadora do campo social e da cultura (SILVA, 2007). Esta autora utilizou e vivenciou a trajetória nômade dos artistas circenses em seu estudo sobre "circo-teatro". Chamados de artistasguias, estes iam se produzindo a partir da própria trajetória, construindo memórias de vida e possibilitando o mapeamento de lugares, instituições, práticas e saberes (MERHY et. al, $2011 ;$ p.14).

Segundo Brasil (2014) mostra que o usuário-guia tem sido utilizado como um relato da produção do cuidado com um usuário que acompanhamos no serviço de saúde. Sendo necessário compreender o usuário-guia como a narrativa de um encontro (SILVA et. al, 2016, p. 252). Contudo este termo desenvolveu-se e agora é reconhecido como usuário cidadão guia (MOEBUS, MERHY, SILVA, 2016; p.52). 
"Deste modo, trazer o usuário e sua narratividade, sua perspectiva para o centro da produção do saber sobre o cuidado, reconstruindo suas trajetórias de vida, seus "inumeráveis estados do ser", é então uma aposta política, ético-estético-política de reafirmar que ele precisa estar no centro da produção do cuidado e do saber"

Nesta pesquisa, pudemos acompanhar uma família toda, sendo assim, a nomearemos como família cidadã guia, emprestando seu conceito do usuário cidadão guia. A seleção para a pesquisa foi realizada a partir das indicações dos profissionais de saúde do serviço no qual a pesquisa foi inserida. Os demais sujeitos foram convidados a produzir a pesquisa conforme eram citados nos encontros e nas narrativas a partir da rede produzida pelo usuário na busca do cuidado.

O cidadão-guia pertencia a uma família assistida pela equipe de estratégia de saúde da família e outros serviços da rede de atenção à saúde do município, residente em um bairro de periferia de alta vulnerabilidade social, em um município de grande porte do sul do País.

Foram incluídos na pesquisa: profissionais da saúde inseridos na atenção básica: enfermeiras, técnicos de enfermagem, assistente social, nutricionista, médicos, agentes comunitários de saúde, auxiliares administrativos, fisioterapeuta e psicóloga. Profissionais do serviço especializado: psicóloga, assistente social, promotor público. E os integrantes do núcleo familiar selecionado: 2 mulheres e 3 homens.

As ferramentas utilizadas no trabalho de campo foram o diário de campo (CECílIO; MERHY, 2003) e as narrativas (ONOKO CAMPOS, 2008) (gravadas e transcritas) que associadas aos encontros e aos autores intercessores produziram o movimento de pesquisa. Os autores intercessores são as referências teóricas que impulsionam a análise do movimento da pesquisa de forma a interseccionar com todos os outros elementos.

Durante o processo da pesquisa, observamos a necessidade de trabalharmos, pesquisadores-pesquisadores e pesquisadores-trabalhadores, a reflexão sobre nossas percepções de cuidado e como isto poderia estar relacionado com a nossa prática na atenção básica, desta forma optamos por realizar a tenda do conto com os trabalhadores da equipe da ESF. Para Félix-Silva (2014). A tenda do conto é:

"É um espaço vivo de exposição de guardados e de experimentação do corpo. Nela, cada participante investe o objeto de desejo por meio da palavra, de maneira que o objeto de afetação ganha vida com as vozes, a narrativa de quem faz o conto e a fala e o silêncio de quem escuta cada participante que se anuncia" (Félix-Silva, 2014, p.16).

Desta forma, foi proposto para a equipe uma oficina reflexiva, utilizando como ferramenta a Tenda do Conto, e este processo será relatado a seguir.

\section{Desenvolvimento}

A família acompanhada pela equipe de saúde é composta pela mãe e 4 filhos dependentes. Sendo que dois deles apresentam necessidades em saúde de alta demanda relacionada à saúde mental, residem na periferia do município, recebem benefícios de programas sociais do Governo e auxílio de vizinhos, instituições religiosas e filantrópicas. Além das dificuldades locais (como violência, controle social por meio do tráfico e pobreza) a família convive com o histórico de violência contra mulher e abuso sexual. Desta forma sua luta pelo acesso aos serviços de saúde reflete muito mais do que a necessidade gerada pelo corpo biológico.

Na busca pelo cuidado, a mãe teceu sua própria rede, formada por vários profissionais de saúde em diferentes pontos da Rede de Atenção, além de profissionais de outros setores e serviços públicos. Contudo, seu maior vínculo era com a equipe da ESF, pois, já conhecia os trabalhadores e, principalmente, sabia com quem podia contar. 
Todavia, o entendimento da equipe era de que nada mais poderia ser feito pela família. A fala frequente dos trabalhadores demonstrava esgotamento da equipe com o caso, que apesar de não ser o mais complexo da área de abrangência, era a situação que mais sensibilizava.

Diante disso, foi proposto à equipe um momento de discussão sobre a família. Em uma das reuniões semanais a equipe discutiu sobre a família cidadã guia, desta vez, a partir das percepções de cuidado e afetações que cada um tinha sobre o caso, sendo utilizada a ferramenta: Tenda do Conto (Félix-Silva, 2014) que, no primeiro momento propôs uma análise das experiências pessoais e no trabalho sobre o cuidado, em seguida permitiu a análise do caso acompanhado.

O processo auxiliou no deslocamento da forma como o trabalhador enxergava a família. Este momento vivenciado com a equipe promoveu lágrimas, soluços, abraços e empatia que expressavam como cada um estava se sentindo naquele momento, mostrando o modo como compartilhavam o cuidado. Ao final conversamos sobre processo de trabalho e como as ações de cada um interferem na construção do cuidado do outro, e juntos perceberam que nesta família não havia algozes ou vítimas, mas que pessoas que lutam diariamente na tentativa de buscar o melhor para si, de pessoas que querem, assim como nós, se sentirem cuidadas."

\section{Discussão}

O momento da reunião de equipe é um espaço formalmente instituído para que os trabalhadores possam discutir os casos que estão acompanhando. Observou-se neste processo de trabalho que a escolha dos casos a serem visitados em determinado dia é realizada de acordo com a demanda ou com a programação da equipe. São discutidos aspectos relacionados a pedido ou resultados de exames, renovação de receitas e demandas ou desdobramentos da assistência daquela visita. Os atores deste processo executam suas ações de acordo com o que há de instituído e, também, com o que acreditam que seja o ideal de cuidado.

No momento em que realizamos a tenda do conto, durante a reunião, a equipe conversou sobre a concepção de cuidado para cada trabalhador sendo que as significações apresentadas remetiam ao cuidado e às ações relacionadas às figuras maternas (avós/tias) que produziam o cuidado familiar ou, que na percepção de uma trabalhadora, são as responsáveis pela falta de cuidado ou culpadas por problemas familiares. Aqui, observamos uma pista dos fluxos que atravessam e que constituíram o processo de subjetivação dos trabalhadores de saúde, como o Cuidar direcionado a figura materna.

A subjetivação são frutos de experiências individuais, mas sofrem influência de concepções de verdade de um coletivo. Pode-se dizer da subjetividade como aquilo que concorre para a produção de um "si", um modo de existir, um estilo de existência (SOARES, MIRANDA; 2009, p.1). Ou seja, se na minha experiência familiar o cuidado dos filhos é exclusividade da mulher, a sociedade re-afirma que a mulher é quem tem o papel de cuidar, o meu encontro com uma mulher que sugere ausência de produção de cuidado da forma como eu entendo, será ruidoso. Guattari e Rolnik (1996) discutem como o processo de subjetivação, por eles nomeada com subjetivação capitalística, influência em nossas práticas:

Tudo o que é produzido pela subjetivação capitalística - tudo o que nos chega pela linguagem, pela família e pelos equipamentos que nos rodeiam - não é apenas uma questão de ideia, seria uma transmissão de significações por meio de enunciados significantes. Tampouco se reduz a modelos de identidade, ou a identificações com polos maternos, paternos, etc. Trata-se de sistemas de conexão direta entre as grandes máquinas produtivas, as grandes máquinas de controle social, e as instâncias psíquicas que definem a maneira de perceber o mundo (GUATARRI, ROLNIK; 1996, p.27). 
É como se vetores atravessassem indivíduo (de forma sutil), produzindo deslocamentos e influenciando diretamente em suas ações, mas sem que essas ações sejam percebidas como frutos de um processo de subjetivação capitalística, pois uma característica deste processo é influência discreta, mas intensa.

Os atores da produção do cuidado trazem em si processos de subjetivação que direcionam suas práticas a partir do que aprenderam enquanto experiência individual e coletiva. E a depender do encontro com o usuário, poderá produzir um olhar de empatia ou um olhar armado para as necessidades do outro.

Se os atravessamentos do encontro com o usuário produzir empatia, o trabalhador da saúde poderá caminhar ao lado deste usuário e tecnologias leves e duras (Merhy; Feuerwerker, 2009) serão utilizadas, instintivamente, neste encontro; mas se este processo de subjetivação produzir um olhar armado, ou seja, um olhar desconfiado das necessidades do outro, um ponto de vista que não considera o usuário como interlocutor (Slomp Júnior, et. al, 2015) válido do seu processo de cuidado, então este olhar produzirá cegueira sobre as necessidades do usuário.

O não reconhecimento da necessidade do outro é uma construção contínua, com sucessivas aproximações e compõe o nosso cotidiano enquanto trabalhadores da saúde. Pois, a partir de alguns aspectos da vida do usuário, são construídos um enquadramento do usuário, como se fosse uma fotografia, e como apontam Baduy et. al, (2015):

Esta fotografia, como uma imagem em duas dimensões, foi capaz de revelar apenas alguns aspectos da sua vida e da sua saúde, mas também produziu uma certa "verdade" sobre ela - seu diagnóstico - como se este incluísse sua vida-multidão, como se ambos coubessem na mesma fotografia e pudessem se resumir a uma imagem imutável (p.222).

Discussões como estas nos permite revisitar nossas práticas e analisar o quanto subjetivações estão operando enquanto compomos o processo de cuidado do outro. Regimes de verdades (FOUCAULT, 1985a; p. 11) que vem sob forma de condutas morais ou até mesmo éticas, mas que pouco enxerga a vida que há do outro lado, e que dependendo de sua rotulação ou classificação, pouco vale a pena.

Bertoluci, et. al, (p. 2016) corroboram ao afirmar que:

Este lugar de portador da verdade abre certas visibilidades e não outras, muitas vezes causando cegueiras e diminuindo as possibilidades de acessar outros territórios existenciais daqueles com quem nos encontramos no dia a dia do cuidado em saúde (p.191).

Reconhecer que há processo de subjetivação em nossa prática do cuidar apoia o deslocamento do olhar armado (Merhy et. al, 2019) do trabalhador da saúde para um olhar centrado no usuário e suas necessidades. Espaços de conversa já instituídos, como nas reuniões, permitem que a equipe realize o processamento e análise da produção do cuidado. E válido pontuar que a utilização de ferramentas disparadoras da reflexão do trabalho são elementos estratégicos na rotina do serviço. Utilizamos neste caso a Tenda do Conto, trata-se de um processo colaborativo de metodologias participativas, realizada em grupos, que permite ao usuário ou o trabalhador, ser protagonista de sua própria história, a partir do momento que narra suas experimentações e dá voz às suas afecções, é uma prática integrativa de cuidado em saúde (Félix-Silva, 2014).

Trabalhadores que não têm um espaço de reflexão do processo de trabalho, não produzem análise, logo vivem o plano de ação dos outros atores repetindo prática já instituídas com pouco espaço para criatividade, centrada em reprodução de protocolos com prevalência na utilização de tecnologias duras e leve duras, muitas vezes não indo ao encontro às necessidades singulares do usuário, em especial dos usuários complexos, como neste caso. O diálogo entre os integrantes das equipes e entre as equipes de saúde de diferentes estações da rede favorecem a produção do cuidado da família e a continuidade da mesma, pois assim as ações se complementam. 


\section{Considerações Finais}

A pesquisa interferência é uma proposta que permite o caminhar do pesquisador e trabalhador da saúde lado a lado, ambos compartilham seus papéis possibilitando a análise das práticas no cotidiano institucional, constituindo novos territórios e incentivando a construção de novas práticas. Tal estratégia metodológica provoca questionamentos no que já está instituído e convida os trabalhadores (agora pesquisadores) a realizar reflexão dos processos de trabalho até então não questionados, se mostrando uma potente ferramenta de Educação Permanente.

As interferências são produzidas no e pelo trabalhador e abre possibilidades para utilizar ferramentas conforme a necessidade que o território da pesquisa exigir. Na construção da pesquisa com os trabalhadores da ESF, a família cidadã guia deu pistas de como esta equipe produziu o cuidado em saúde no encontro com ela. A partir de então a utilização da ferramenta Tenda do Conto possibilitou auto análise dos modos de cuidar destes trabalhadores, que além de observarem a necessidade de darem vazão ao seus afetos perceberam que realizar a educação permanente em saúde seria um caminho para a prática da reflexão do processo do cuidar. A pesquisa produz conhecimento ao mesmo tempo que produz reflexão e mudança da prática em ato.

\section{Referências}

Abrahão, A.L. et al. O pesquisador in-mundo e o processo de produção de outras formas de investigação em saúde. Lugar Comum (UFRJ), Rio de Janeiro, v. 39, p. 133-144, 2013.

Baduy, R.S; et al. "Mas ele não adere!" - O desafio de acolher o outro que é complexo para mim. In: Merhy, E.E.; Baduy, R.S.; Seixas, C.T.; Almeida, D.E.S.; Slomp Júnior, H. Avaliação compartilhada do cuidado em saúde. Surpreendendo o instituído nas redes. Políticas e Cuidados em Saúde: livro 1. Rio de Janeiro: Hexis; 2016.

BRASIL. Ministério da Saúde. Secretaria de Atenção à Saúde. Departamento de Atenção Básica. Política Nacional de Atenção Básica / Ministério da Saúde. Secretaria de Atenção à Saúde. Departamento de Atenção Básica. - Brasília: Ministério da Saúde, 2012.

Cecílio, L.C.O.; Merhy, E.E. A integralidade do cuidado como eixo da gestão hospitalar. In: Pinheiro, R.; Mattos, R.A. (Org.). Construção da integralidade: cotidiano, saberes e práticas em saúde. Rio de Janeiro: IMS/UERJ/ABRASCO, v. 1, 2003, p. 197-210.

Deleuze, G.; Guattari, F. Introdução: Rizoma. In: Deleuze, G.; Guattari, F. Mil platôs: capitalismo e esquizofrenia. Rio de Janeiro: Ed. 34, $1^{\text {a }}$ edição 1995 e $2^{\underline{a}}$ Reimpressão em 2000. v.1, p.1037.

Eps Em Movimento. Refletindo sobre ferramentas analisadoras. 2014. Disponível em: file:///C:/Users/usuario/Downloads/Refletindo\%20sobre\%20ferramentas\%20analisadoras.pdf. Acesso em: 27 jun. 2018.

Faria, H.P.; Werneck, M.A.F.; Santos, M.A.; Teixeira, P.F. O processo de trabalho em seus componentes. In: Processo de trabalho em saúde/Horácio Faria, Marcos Werneck, Max André dos santos. - $2^{\underline{a}}$ ed. - Belo Horizonte: Nescon/UFMG, Coopmed., 2009. 68p.: il., 22x27cm. Disponível em: file:///C:/Users/usuario/Downloads/processo-trabalho-saude2009.pdf. Acesso em: 16 mar. 2021.

Félix-Silva, A. V. et al. A tenda do conto como prática integrativa de cuidado na atenção básica / Natal: Edunp, 2014.78p. ISBN: 978-85-8257-014-2.

Guatarri, F.; Rolnik, S. Micropolítica - Cartografia do Desejo. 4ª Edição Petrópolis: Editora Vozes. 1996. 327p.

Marandola, T.R; Marandola, C.M.R; Melchior,R. et al. Educação Permanente em Saúde: Conhecer para Compreender. Disponível em: http://www.ccs.uel.br/espacoparasaude/v10n2/Artigo8.pdf

Moebus, R. L. N. Pesquisa interferência desde Heisenberg. In: Merhy, E.E; Baduy, R.S; SEIXAS, C.T; ALMEIDA, D.E.S.; SLOMP JÚNIOR, H. Avaliação compartilhada do cuidado em saúde. Surpreendendo o instituído nas redes. Políticas e Cuidados em Saúde: livro 1. Rio de Janeiro: Hexis; 2016. 
Moebus, R. L. N; Merhy, E.E; Silva, E. O usuário-cidadão como guia.Como pode a onda elevar-se acima da montanha? In: Merhy, E.E; Baduy, R.S; Seixas, C.T; Almeida, D.E.S.; Slomp Júnior, H. Avaliação compartilhada do cuidado em saúde. Surpreendendo o instituído nas redes. Políticas e Cuidados em Saúde: livro 1. Rio de Janeiro: Hexis; 2016.

Merhy, E.E. et al. Diálogos pertinentes: micropolítica do trabalho vivo em ato e o trabalho imaterial: novas subjetivações e disputas por uma autopoiese anticapitalística no mundo da saúde. Lugar Comum: Estudos de Mídia, Cultura e Democracia, Rio de Janeiro, n. 33-34, p. 89-103, jan./ago., 2011.

Merhy, E.E. et al. Rede Básica, Campos de força, Micropolitica: implicações para gestão e cuidado em saúde. Saúde debate 43 (spe6) 10 Jul 20202019 Disponivel em: https://www.scielosp.org/article/sdeb/2019.v43nspe6/70-83/

Onocko Campos, R.T.; Furtado, J.P. Narrativas: utilização na pesquisa qualitativa em saúde. Rev. Saúde Pública, São Paulo, v. 42, n. 6, p. 1090-1096, Dec. 2008. Disponível em: http://www.scielo.br/scielo.php. Acesso em: 08 out. 2017.

Rodrigues, M.P.; Araújo, M.S.S. O fazer em saúde: um novo olhar sobre o processo de trabalho na estratégia saúde da família. Natal: UFRN/UFPE, 2003.

Rolnik, S. Cartografia sentimental: transformações contemporâneas do desejo / Suely Rolnik - $2^{a}$ edição, Porto Alegre: Sulina; Editora da UFRGS, 2016. 248 p.

Silva, E. Circo-teatro: Benjamim de Oliveira e a teatralidade circense no Brasil. São Paulo: Altana, 2007.

Slomp Junior, H.; Feuerwerker, L.C.M.; Land, M.G.P. Educação em saúde ou projeto terapêutico compartilhado? O cuidado extravasa a dimensão pedagógica. Ciênc. Saúde coletiva, Rio de Janeiro, v. 20, n. 2, p. 537-546, Fev. 2015. Disponível em: https://doi.org/10.1590/141381232015202.00512014. Acesso em: 17 mar. 2021.

Soares, L.B.; Miranda, L. L. Produzir subjetividades: o que significa? Estudos e Pesquisa em Psicologia, Rio de Janeiro, v. 9, n 2, p.408-424. 2009. Disponível em: http://pepsic.bvsalud.org/scielo.php. Acesso em: 24 jun. 2018. 